\title{
Factors Affecting Knowledge Acquisition among Adult Workers in Online Informal Learning Activities
}

\author{
Horng-Ji Lai ${ }^{1^{*}}$ \\ ${ }^{1}$ Department of Counselling Psychology and Human Resource Development, National Chi Nan University, Puli, Nantou County, \\ TAIWAN
}

Received 16 June 2017 • Revised 2 October 2017 • Accepted 31 October 2017

\begin{abstract}
The purpose of this study was to develop and test a research model that investigates the factors influencing knowledge acquisition among adult workers participating in online informal learning activities. A total of 342 adult workers, all of whom were civil servants working for the government in Taiwan, participated in this study. A survey instrument was used to assess their perceived abilities in information querying, information differentiation, online communication self-efficacy, information evaluation and extraction, and knowledge acquisition. A Structural Equation Modeling was performed using Partial Least Squares regression for data exploration and model estimation. The results of this study indicate that information querying, significantly affected the participants' information differentiation performance. The construct of information differentiation yielded a positive influence in the respondents' online communication self-efficacy and information evaluation and extraction. Moreover, information evaluation and extraction was found to be a significant predictor influencing adult workers' knowledge acquisition. The findings imply that organizations should consider including information literacy training in training initiatives and provide friendly online collaborating tools to enhance employees' online informal learning experiences.
\end{abstract}

Keywords: online informal learning, adult learning, workplace learning, information seeking, knowledge acquisition

\section{INTRODUCTION}

Informal learning is the most prevalent form of adult learning, and accounts for the majority of learning occurring in the workplace (Eraut, 2004; Merriam, Caffarella, \& Baumgartner, 2007; Marsick, Watkins, Callahan, \& Volpe, 2009). Many organizations have realized that informal learning is a crucial practice for updating and developing the knowledge and skills of workers adapting to a $21^{\text {st }}$ century working environment. Organizational training initiatives are responding to the challenges of this new work environment by creating effective and friendly informal learning environments, especially through the use and application of information technology tools (Spagnoletti, Za, \& North-Samardzic, 2013). In this respect, not only the private but also the public sector strives to introduce solutions to encourage their employees to create, enhance and share knowledge through online informal learning means (Stoffregen, Pawlowski, \& Pirkkalainen, 2015). On the other hand, the popularity of mobile devices, such as tablet computers and smartphones, has made informal learning more accessible and flexible (Clough, Jones, McAndrew, \& Scanlon, 2008; Macdonald \& Chiu, 2011; Zhang, Yin, David, Xiong, \& Niu, 2016). Given the evidence that technology rich environments provide easy and efficient ways for working adults to acquire knowledge related to their jobs, and connect with colleagues and people outside of work, it is therefore important to understand the impact of online informal learning on adult workers along with the factors influencing their knowledge acquisition in the digital learning environment.

Recent studies (Berg \& Chyung, 2008; Wihak \& Hall, 2011; Puijenbroek, Kroon, \& Timmerman, 2014) have shown that developments in web technology and its adoption inside and outside of the workplace, have led to a rapid rise in participation in informal learning activities. The most significant quantum leap came with 


\section{Contribution of this paper to the literature}

- The research model provides a more comprehensive insight into online information seeking and sharing behavior, while exploring adult workers' perceived abilities towards knowledge construction in the context of online informal learning.

- The present findings show that critical elements of the ISP model could contribute significantly in predicting adult workers' engagement in online informal learning activities.

- The research results suggest that information literacy training related to information seeking needs to be arranged in organizations' training initiatives, and the concepts of the ISP model can be incorporated into the training courses designed to empower employees' digital information literacy.

advancements in Web 2.0 tools and mobile technologies, which provided highly interactive network environments for learners to share information and exchange ideas quickly (Gu, Churchill, \& Lu, 2014). With the emergence and adoption of Web based technologies, emphasis on learning has shifted from more traditional instruction-centered learning to more learner-centered models that encourage learners to utilize appropriate tools to discover new knowledge and to communicate with others more independently. Milligan, Littlejohn, and Margaryan (2014) further identified four learning behaviors that working adults performed while engaging in informal learning in digital networks. The four behaviors are consuming, creating, connecting, and contributing. Each behavior has corresponding Web technology tools that allow learners to perform informal learning tasks, such as search engines for consuming, note taking tools for creating, microblogging tools for connecting, and collaborating platforms for contributing. These tools, such as Evernote, Twitter, blogs, and Google Docs, allow learners to track the evidence of their learning and they are accessible to their colleagues. Milligan et al. (2014) argued that technology supports the enactment of these behaviors and empowers learners to contribute new knowledge back to the learning network, which in turn leads to effective knowledge flow.

To better understand how to achieve effective online informal learning in the workplace, it is necessary to investigate the factors affecting the effectiveness and behavior of adult workers participating in online learning environments. Kuhlthau's (1991) Information Search Process (ISP) model outlines the process of information seeking behaviors that demonstrate the critical elements learners perform during online informal learning activities. The ISP model mainly describes the affective, cognitive, and physical aspects of learners' information seeking behavior and knowledge acquisition involved in the process (Mills, Knezek, \& Khaddage, 2014; Savolainen, 2015). In addition, interpersonal communication, utilizing various types of social media, also plays an important role in facilitating how learners acquire knowledge (Mills et al., 2014; Puijenbroek et al., 2014). Lohman (2009) asserted that behavioral activities associated with cognitive steps, need to be considered while evaluating how a learner engages in informal learning activities. Taking these concepts into account, the purpose of this study was to develop a research model that investigates the factors influencing knowledge acquisition among adult workers participating in online informal learning activities.

\section{LITERATURE REVIEW}

Based on the research work of Marsick et al. (1999), informal learning can be defined as a process initiated by an intent to learn, followed by experience and action, feedback seeking, and reflection (Noe et al., 2013). Lohman (2009) further identified informal learning, relating to the workplace, as those activities arising from people in workplace settings that help them to develop professional knowledge and skills. Forms of informal learning, according to Schugurensky (2000), can be categorized into self-directed learning, incidental learning, and socialization. Lohman (2009) listed examples of informal learning that happen in the workplace that include talking and sharing resources with others, searching the Internet, and experimenting with new techniques. In recent years, utilizing information technology in various educational or training contexts is increasingly concerned with issues associated with informal learning. Related empirical studies (Kassens-Noor, 2012; Milligan et al., 2014; Puijenbroek et al., 2014; Sackey, Nguyen, \& Grabill, 2015) provide supporting evidence concerning the positive effects of information communications technology (ICT) tools and their adoption by adult workers participating in informal learning activities in the workplace.

In a study conducted by Berg and Chyung (2008), access to computer technology and physical proximity to colleagues were important factors influencing how workers behave and engage in informal learning. Online environments are capable of providing services that enable workers to retrieve information and communicate with their colleagues. Based on arguments found in related literature (Berg \& Chyung, 2008; Ho, Kuo, \& Lin, 2012; Spagnoletti et al., 2013), searching for relevant information on the Internet and interacting with others seems to be two important activities that adult workers frequently engage in while participating in the online informal learning process. It is, therefore, critical for training coordinators to recognize important elements of adult workers' information search behavior and their information-to-knowledge experiences in the online context. 
Kahlthau's ISP model provides a detailed and clear picture of the information search process (Savolainen, 2015). The ISP model, proposed by Kahlthau (1991), depicts six stages (i.e. initiation, selection, exploration, formulation, collection, and presentation) of information search activity, that learners implement while searching online that can be beneficial for directing learning activities (Mills et al., 2014). According to Kahlthau (1991), the ISP model consists of three realms; the affective (feelings), the cognitive (thoughts), and the physical (actions) realms, which are common to each stage. Actions taken in the six stages include seeking background information (initiation and selection), seeking relevant information (exploration and formulation) and finally focused information (collection and presentation). Although the ISP model was established in and for traditional library environments, it has been tested in technology driven environments and has shown itself to be effective in understanding the behavior and knowledge acquisition of information seeking learners (Mills et al., 2014). In an online informal learning context, searching for information on the Internet is the easiest and most convenient way for learners to solve problems when they recognize a need for information or lack related knowledge. During the information search process, learners diagnose their Internet self-efficacy and reflect on previous knowledge and actions to filter information and select trusted information sources to consume (Berg \& Chyung, 2008; Milligan et al., 2014). Tabatabai and Shore (2005) indicated that learners with higher information seeking knowledge, computer knowledge, and information evaluation ability tend to increase the chance of a successful search on the Web. A recent study (Feng \& Ha, 2016) also discovered that higher information literacy skills in information perception, selection, utilization, and evaluation, can help individuals to develop better lifelong learning attitudes. In the workplace, informal learning networks are increasingly mediated through ICT tools, which influence information seeking decisions. Thus, learners' skills in information querying, information differentiation, and information evaluation and extraction, determine the quality of acquired knowledge.

Knowledge sharing through interaction is an important activity in online informal learning environments. Individuals may connect to their personal network to seek advice when they are not confident about the information they browse or if they find it difficult to make a distinction between right and wrong. Lohman (2006, 2009) found that talking with others was one of the most frequently used informal learning activities for public school teachers and IT professionals. In a similar manner, Hung, Chou, Chen, and Own (2010) identified online communication self-efficacy was a critical element to assess learner readiness for online learning. A recent investigation (Nikolova, Van Ruysseveldt, De Witte, \& Syroit, 2014) found that learning from colleagues and supervisors were identified as relevant dimensions of work-based learning. Online communication tools, such as email, discussion forums, instant messaging, and social media, complement learning activities. Li, Shi, and Dang (2014) indicated that online communication has become an important way for mature learners to have social interaction. This suggests that the ability to communicate with others plays a significant role in determining the effectiveness of online informal learning among adult learners.

\section{RESEARCH MODEL AND HYPOTHESES DEVELOPMENT}

The research model was developed to enable consideration of the relationships between information querying, information differentiation, online communication self-efficacy, information evaluation and extraction, and knowledge acquisition. Definitions of all constructs in the model are described in Table 1.

Table 1. Definitions of constructs

\begin{tabular}{ll}
\hline Construct & Definitions \\
\hline information querying & $\begin{array}{l}\text { The extent to which an individual perceives his or her ability to identify keywords, choose } \\
\text { search engines, and determine search features. }\end{array}$ \\
\hline Information differentiation & $\begin{array}{l}\text { The extent to which an individual perceives his or her ability to judge the reliability of } \\
\text { information. }\end{array}$ \\
\hline $\begin{array}{l}\text { Online communication self- } \\
\text { efficacy }\end{array}$ & $\begin{array}{l}\text { The extent to which an individual perceives his or her ability to use online communication } \\
\text { tools to ask questions, share information, and initiate discussions. }\end{array}$ \\
\hline $\begin{array}{l}\text { Information evaluation and } \\
\text { extraction }\end{array}$ & $\begin{array}{l}\text { The extent to which an individual perceives his or her ability to filter, evaluate, and extract } \\
\text { relevant information from the Internet resources. }\end{array}$ \\
\hline Knowledge acquisition & $\begin{array}{l}\text { The extent to which an individual believes that online informal learning can help him or her } \\
\text { to acquire knowledge. }\end{array}$ \\
\hline
\end{tabular}

Previous research (Kuhlthau, Heinström \& Todd, 2008; Hung et al., 2010; Milligan et al., 2014; Mills et al., 2014) suggests that information query skills could influence information differentiation. When learners are not confident about the information source, they may ask others via online communication tools (Oh, Ozkaya, \& LaRose, 2014; Liu, 2017). Therefore, information differentiation and online communication self-efficacy affect information evaluation and extraction, which in turn leads to knowledge creation (Mills et al., 2014). The model constructs and their relationships are illustrated in Figure 1. In this study, it is supposed that online informal learning starts with 


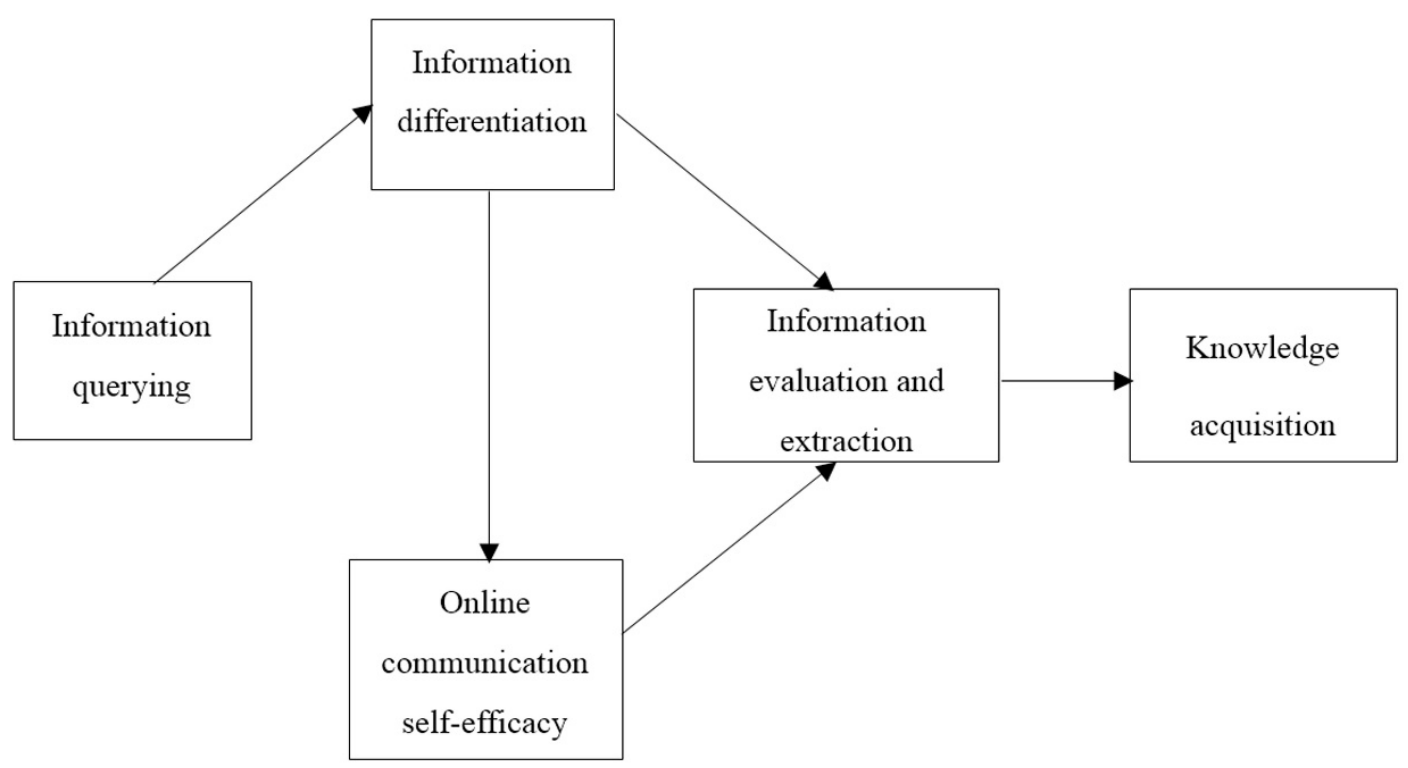

Figure 1. The hypothesized model of the online information learning

information querying. Information differentiation is initiated after browsing and surveying the online information. At this stage, the workers/learners may reflect on their previous knowledge or ask colleagues or supervisors in order to confirm information pertinent to their needs. Finally, the collected information is further evaluated and verified for the purpose of solving problems and constructing knowledge in order to act in the new situation.

Building on the proposed model, the following hypotheses were formulated:

H1: Information querying has a positive effect on information differentiation.

H2: Information differentiation has a positive effect on online communication self-efficacy.

H3: Information differentiation has a positive effect on information evaluation and extraction.

H4: Online communication self-efficacy has a positive effect on information evaluation and extraction.

H5: Information evaluation and extraction have a positive effect on knowledge acquisition.

\section{METHODOLOGY}

\section{Study Site and Participants}

This study was conducted with the help of the Regional Civil Service Development Institute, located in central Taiwan. The participants for this study consisted of fulltime working civil servants. In accordance with Taiwanese government regulations, all civil servants were required to undertake a number of hours of training, via courses offered online, through learning portals each year. Informal learning tools, such as discussion forums and weblog, were incorporated into the learning portals. A reward system was created to encourage civil servants to utilize the online informal learning tools. In addition to complete online training courses, civil servants can receive awards (e.g. employee recognition and gift vouchers) for posting certain amount of messages and answering their colleagues' questions in the discussion forums. Thus, all participants were equipped with the necessary knowledge to use computers and navigate Internet applications, and they were familiar with the concept and practice of informal learning. Data was collected via a questionnaire format. Survey questionnaires were distributed across 12 lectures, and were disseminated following the participants' attendance of soft skill training courses on site. A total of 350 questionnaires were collected, and 342 were valid for analysis $(97.71 \%)$. Participants were $51.5 \%$ female (n $=176)$ and $48.5 \%$ male $(n=166)$. Regarding their age, $19.35 \%(n=66)$ of participants were under 30 years of age, $29.5 \%(n=101)$ were between 31 and 40 years of age, $38.5 \%(n=125)$ were between 41 and 50 years of age, and $14.5 \%(n=50)$ were 51 years of age or older. 


\section{Instrument}

The survey instrument used was developed based upon a review of current literature along with past studies concerning the objective of the study. The variables measured include the following: information querying, information differentiation, online communication self-efficacy, information evaluation and extraction, and knowledge acquisition. The constructs of information querying (e.g., I am confident in using the search engines to find or gather information), information differentiation (e.g., Based on my experience, I know which websites offer highly accurate information), and information evaluation and extraction (e.g., I am able to make better decisions based on information from the Internet resources) were modified from studies carried out by Hung et al. (2010) and Lai and Wang (2012). The online communication self-efficacy (e.g., I am confident in using online tools to effectively communicate with others) construct was modified from scales developed by Hung et al. (2010) and Nikolova et al. (2014). Finally, the survey items of knowledge acquisition dimension (e.g., I can integrate information into a suitable answer to solve problems) were revised from an earlier study conducted by Lai and Wang (2012). All questionnaire items were measured using a 7-point Likert-type scale, ranging from "strongly disagree (1)" to "strongly agree (7)". The survey instrument also collected the respondents' demographic information, such as gender, age, and educational background. In order to ensure the survey instrument provided trustworthy data, 5 university faculty members were invited to review the survey questions. A few changes were made according to the panelists' suggestions. After revision, the official survey was administered to the participants.

\section{Data Analysis}

The statistical analysis method used for this research was Partial Least Squares (PLS), a technique for conducting structural equation modeling. PLS supports both exploratory and confirmatory analysis, and it focuses on identifying the variance and relationships between constructs and variables (Chin, 1998; Hair, Ringle, \& Sarstedt, 2011). Hair et al. (2011) noted that PLS is the preferred statistical method when the research objective is theory development and prediction. In addition, PLS is advantageous when the research model is relatively complex and the measures not well established (Chin, 1998). Therefore, PLS was appropriate for analysis in this study.

\section{RESULTS}

\section{Descriptive Findings}

Table 2 summarizes the mean (M) scores and standard deviations (SD) of the participants' responses to each construct. According to Table 2, the participants scored highest on the information evaluation and extraction construct, and the lowest on online communication self-efficacy.

Table 2. Descriptive statistics of the study constructs

\begin{tabular}{lll}
\hline Construct & Mean & Std. deviation \\
\hline Knowledge acquisition & 5.511 & 0.902 \\
\hline Information evaluation and extraction & 5.601 & 0.845 \\
\hline Information differentiation & 5.253 & 0.922 \\
\hline Information querying & 5.376 & 0.901 \\
\hline Online communication self-efficacy & 3.867 & 1.233 \\
\hline
\end{tabular}

\section{Evaluation of the Measurement Model}

Analysis of the measurement PLS model involved the estimation of item reliability, convergent validity, and discriminant validity. Reliability was evaluated using composite reliability (CR) and Cronbach's alpha. As shown in Table 3, all loading of items were greater than 0.7 and significant at 0.001 level, and composite reliability values were above the 0.7 threshold, as recommended by Fornell and Larcker (1981). Convergent validity was assessed using average variance extracted (AVE). The AVE values of all five constructs were greater than 0.5, a threshold level considered acceptable (Hair et al., 2006). Cronbach's alpha value was calculated for each construct, and all values ranged from 0.880 to 0.911 , passing the suggested value of 0.7 (Nunnally, 1978) indicating good reliability. 
Table 3. Results of item loadings, Cronbach's alpha, composite reliability, and AVE

\begin{tabular}{|c|c|c|c|c|c|}
\hline Construct & Item & Item loading & Cronbach's Alpha & Composite Reliability & $\begin{array}{c}\text { Average Variance } \\
\text { Extracted (AVE) }\end{array}$ \\
\hline \multirow{4}{*}{ Knowledge acquisition (KA) } & KA1 & 0.894 & \multirow{4}{*}{0.880} & \multirow{4}{*}{0.918} & \multirow{4}{*}{0.737} \\
\hline & KA2 & 0.915 & & & \\
\hline & KA3 & 0.842 & & & \\
\hline & KA4 & 0.778 & & & \\
\hline \multirow{5}{*}{$\begin{array}{l}\text { Information evaluation and } \\
\text { extraction (IEE) }\end{array}$} & IEE1 & 0.786 & \multirow{5}{*}{0902} & \multirow{5}{*}{0.927} & \multirow{5}{*}{0.718} \\
\hline & IEE2 & 0.842 & & & \\
\hline & IEE3 & 0.868 & & & \\
\hline & IEE4 & 0.885 & & & \\
\hline & IEE5 & 0.854 & & & \\
\hline \multirow{4}{*}{$\begin{array}{l}\text { Information differentiation } \\
\text { (ID) }\end{array}$} & ID1 & 0.834 & \multirow{4}{*}{0.868} & \multirow{4}{*}{0.910} & \multirow{4}{*}{0.716} \\
\hline & ID2 & 0.839 & & & \\
\hline & ID3 & 0.884 & & & \\
\hline & ID4 & 0.826 & & & \\
\hline \multirow{5}{*}{ Information querying(IQ) } & IQ1 & 0.731 & \multirow{5}{*}{0.885} & \multirow{5}{*}{0.916} & \multirow{5}{*}{0.687} \\
\hline & IQ2 & 0.862 & & & \\
\hline & IQ3 & 0.887 & & & \\
\hline & IQ4 & 0.818 & & & \\
\hline & IQ5 & 0.838 & & & \\
\hline \multirow{5}{*}{$\begin{array}{l}\text { Online communication self- } \\
\text { efficacy(OCS) }\end{array}$} & OCS1 & 0.820 & \multirow{5}{*}{0.911} & \multirow{5}{*}{0.934} & \multirow{5}{*}{0.740} \\
\hline & OCS2 & 0.905 & & & \\
\hline & OCS3 & 0.919 & & & \\
\hline & OCS4 & 0.795 & & & \\
\hline & OCS5 & 0.854 & & & \\
\hline
\end{tabular}

Table 4. Correlation of construct and square roots of AVEs

\begin{tabular}{cccccc}
\hline Construct & KA & IEE & ID & IQ & OCS \\
\hline Knowledge acquisition (KA) & 0.859 & & & & \\
\hline Information evaluation and extraction (IEE) & 0.730 & 0.848 & & & \\
\hline Information differentiation (ID) & 0.720 & 0.588 & 0.846 & & \\
\hline Information querying(IQ) & 0.636 & 0.556 & 0.804 & 0.829 & 0.860 \\
\hline Online communication self-efficacy(OCS) & 0.346 & 0.267 & 0.428 & 0.329 & 0 \\
\hline
\end{tabular}

Table 5. Heterotrait-Monotrait Ratio (HTMT)

\begin{tabular}{ccccc}
\hline Construct & KA & IEE & ID & IQ \\
\hline Information evaluation and extraction & 0.820 & & & \\
\hline (IEE) & $(0.713 ; 0.894)$ & & & \\
\hline \multirow{2}{*}{ Information differentiation (ID) } & 0.821 & 0.661 & & \\
& $(0.732 ; 0.886)$ & $(0.527 ; 0.763)$ & & \\
\hline \multirow{2}{*}{ Information querying(IQ) } & 0.724 & 0.628 & 0909 & \\
\hline \multirow{2}{*}{ Online communication self-efficacy(OCS) } & $(0.598 ; 0.814)$ & $(0.477 ; 0.746)$ & $(0.854 ; 0.948)$ & 0.357 \\
& $(0.284 ; 0.494)$ & $(0.166 ; 0.409)$ & $(0.373 ; 0.574)$ & $(0.236 ; 0.463)$ \\
\hline
\end{tabular}

For satisfactory discriminant validity, the square root of AVEs should be greater than the correlations between the construct and other constructs in the model (Fornell \& Larcker, 1981). Table 4 shows the correlation of constructs and the square root of AVEs. In addition, the Heterotrait-Monotrait Ratio (HTMT) of correlations was examined to assess the discriminant validity as suggested by Henseler, Ringle, and Sarstedt (2015). The HTMT values and the corresponding confidence intervals deriving from a bootstrapping procedure are outlined in Table 5. By using the criteria of HTMT inference, neither lower nor upper confidence intervals include the value of 1.0 (Henseler et al., 2015). The instrument demonstrated acceptable discriminant validity.

\section{Testing of the Measurement Model}

A bootstrapping resampling estimation was used to assess the structural model, as recommended by Chin (1998). A testing of the structural model included the estimation of path coefficient and $\mathrm{R}^{2}$ value which indicate predictive power of the model. Path coefficients explain the strength of the relationships between two variables, 
and the $\mathrm{R}^{2}$ for the dependent variables, provides estimates of variance explained by the independent variables. The significance of all paths was examined using 1000 bootstrap runs. The results of the analysis of the structural model are shown in Table 6. Figure 2 depicts the structural model showing path coefficients and $\mathrm{R}^{2}$ for dependent variables. The path coefficients indicate that $\mathrm{H} 1, \mathrm{H} 2, \mathrm{H} 3$, and $\mathrm{H} 5$ were confirmed. The results show that Information querying has a significant effect on Information differentiation $(\beta=0.804, p<0.001)$. Information differentiation positively impacts Online communication self-efficacy $(\beta=0.329, \mathrm{p}<0.001)$ and Information evaluation and extraction $(\beta=0.580, p<0.001)$. Also, Information evaluation and extraction is positively associated with Knowledge acquisition $(\beta=0.730, p<0.001)$. However, $\mathrm{H} 4$ was not supported. Online communication self-efficacy was not found to influence Information evaluation and extraction $(\beta=0.019, p=0.709)$. The $R^{2}$ values for each dependent variable indicate the model was able to count $64.7 \%$ of the variance in Information differentiation, $34.6 \%$ of variance in Information evaluation and extraction, $10.8 \%$ of variance in Online communication self-efficacy, and $53.3 \%$ of the variance in Knowledge acquisition. In Table 6, the effect size $\left(f^{2}\right)$ can be seen where H1, H3, and H5 depicted large effect sizes, whereas H2 presented small effect size and H4 had no effect as suggested by Cohen (1988). Furthermore, the predictive relevance of the research model was evaluated by using a blindfolding procedure. The Stone-Geisser's $\mathrm{Q}^{2}$ values (ranged from 0.073 to 0.431 ) are greater than zero, indicating that all endogenous constructs show adequate predictive relevance (Hair Jr, Hult, Ringle, \& Sarstedt, 2016).

Table 6. Results of structural model analysis

\begin{tabular}{ccccccc}
\hline Hypotheses & Relationship & Std. Beta & Std. Error & t-value & p-value & $\boldsymbol{f}^{2}$ \\
\hline $\mathrm{H} 1$ & $\mathrm{IQ} \rightarrow \mathrm{ID}$ & 0.804 & 0.027 & 30.093 & 0.000 & 1.834 \\
\hline $\mathrm{H} 2$ & $\mathrm{ID} \rightarrow \mathrm{OCS}$ & 0.329 & 0.052 & 6.270 & 0.000 & 0.121 \\
\hline $\mathrm{H} 3$ & $\mathrm{ID} \rightarrow \mathrm{IEE}$ & 0.580 & 0.066 & 8.815 & 0.000 & 0.421 \\
\hline $\mathrm{H} 4$ & $\mathrm{OCS} \rightarrow \mathrm{IEE}$ & 0.019 & 0.052 & 0.373 & 0.709 & 0.000 \\
\hline $\mathrm{H} 5$ & $\mathrm{IEE} \rightarrow \mathrm{KA}$ & 0.730 & 0.049 & 14.681 & 0.000 \\
\hline
\end{tabular}

Note: $f^{2}: 0.02:$ small; 0.15 : medium; 0.35: large

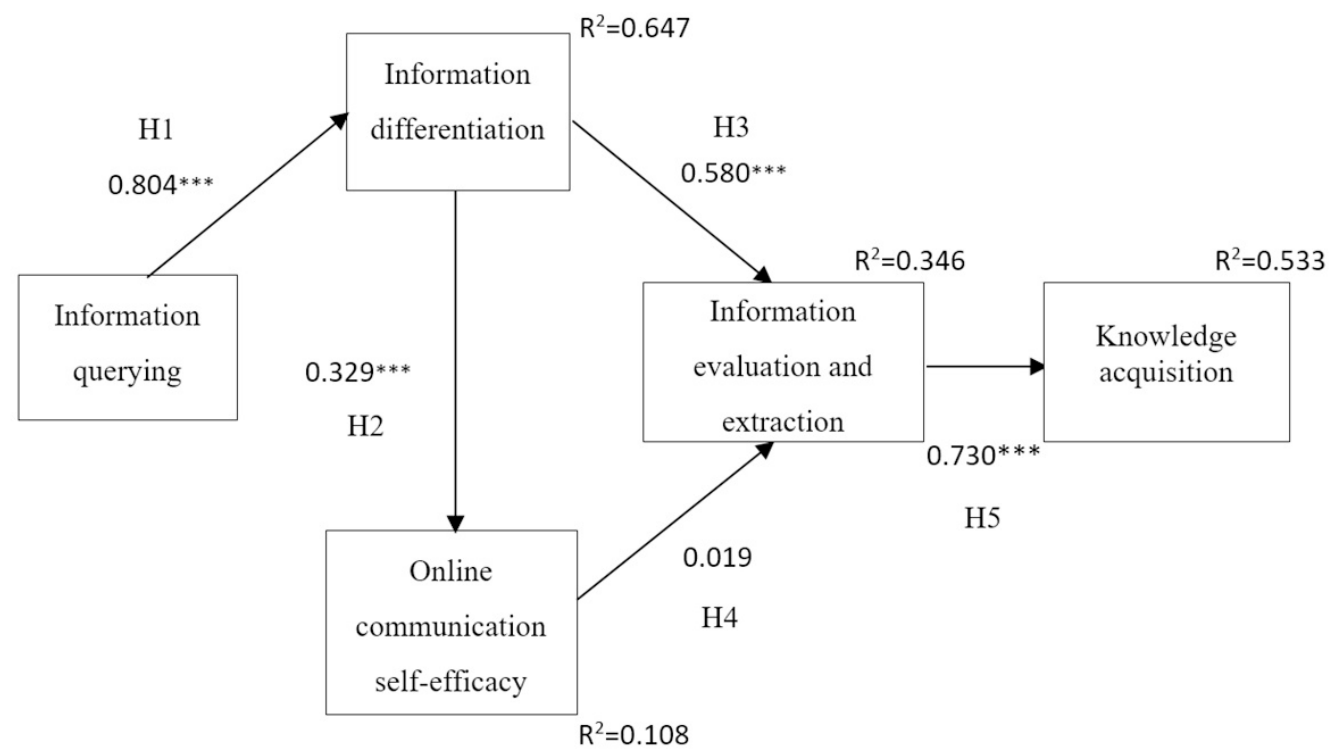

$* * * p<0.001$

Figure 2. PLS analysis of the proposed model

\section{DISCUSSION}

The research model used in this study, was built on existing literature concerning online learning activities, and considered the impact of online information seeking behavior on knowledge acquisition among adult workers. This study presents a conceptual framework for understanding the online informal learning behavior of adult workers. The results of the PLS regression analysis provided crucial confirmation on both the significance of the model and its measures. The findings clearly suggest that critical components during a learner's information seeking process affected knowledge construction while participating in online informal learning. 
Information querying was found to be a significant factor affecting information differentiation. This is in line with previous studies (Kuhlthau, 1991; Kuhlthau et al., 2008) which suggest that adult workers skills in information querying impact their performance in judging online information. According to Kuhlthau et al. (2008), availability of information, lack of previous knowledge, and finding precise information, were the top difficulties students encountered during the inquiry process. This implies that organizations need to provide training using search engines and related online databases to their employees. On the other hand, the study revealed that adult workers' ability in information differentiation is positively correlated to their online communication self-efficacy and information evaluation and extraction skills. This seems to be a logical finding, given the fact that when adult workers can distinguish reliable information from search results, they may be able to carefully evaluate the information and further collect information pieces relevant to their needs. A past study (Walraven, Brand-Gruwel, \& Boshuizen, 2009) has concluded that college students who did not explicitly evaluate their search results, information or sources, may expect a less optimal product. This finding suggests that training initiatives need to include courses to foster workers' online information judgement skills. In addition, the significant path coefficient showed that the higher information differentiation ability the workers had, the higher the likelihood that they might develop better online communication skills that can help them to obtain information quickly. The charting learning pathways of 4C behaviors (Consume, Connect, Create, and Contribute) proposed by Milligan et al. (2014) indicated that individuals with similar learning goals tend to contribute useful information and connect with people in their personal learning network. In an investigation conducted by Kao and Chien (2017), they also suggested that in order to improving adult learners' approaches to learning and strengthen their learning performances in Internetbased environments, relevant web-based tools must be provided. In light of this argument, online communication tools such as discussion forums, blogs, and social networking applications can be incorporated into an organization's learning management system, to encourage adult workers to exchange ideas and share information in association with work-related issues.

In this study, an insignificant correlation of online communication self-efficacy to information evaluation and extraction was found. The result agrees with a previous study (Puijenbroek et al., 2014) indicating how employees might not make optimal use of communication tools in sharing information. From the descriptive statistics, online communication self-efficacy dimension was rated lowest by the participants. These findings suggest that organizations can arrange training courses to help their employees to effectively use online communication tools, such as discussion forums and social media, and practically apply them to work-related learning activities. A recent study (Liu, 2017) found evidence that higher online communication self-efficacy is associated with higher selfregulated learning ability. According to Liu (2017), adult learners who can pursue external help from knowledgeable people via online communication, can develop better self-regulated learning strategies and emotions that foster informal learning competencies. The study also found that information evaluation and extraction is a significant predictor of knowledge acquisition among the respondents. The result was expected, as noted by Kuhlthau et al. (2008) and Mills et al. (2014), who argue that when learners engage in complex information seeking behavior, it can be useful for directing learning in digital technology-rich environments. This implies that guidance and instruction needs to be emphasized on attributes relating to the information inquiry process. More external support from the workplace is needed to enhance adult workers' online information literacy toward learning.

The results of this study confirm previous studies that adult workers' information literacy and online communication skills positively impact their knowledge construction while engaging in online informal learning activities in the workplace. For example, Lohman (2009) investigated factors affecting engagement in informal learning activities of 143 IT professionals in a survey. Survey findings revealed that IT professionals relied heavily on searching the Internet to acquire information and talking with others when they were not able to address their learning needs. Similarly, in the usage of Web 2.0 applications (such as blogs, Wikis, and group messaging) within the organization, Ajjan, Hartshorne, and Buechler (2012) designed a model to test the relationship between knowledge management performance and use of Web 2.0 applications of working adults. They found that the higher the use of Web 2.0 applications within organizations, the higher knowledge that was created, which promoted learning activities and stimulated new discussions. The findings from this study indicate that the model can be useful for explaining information seeking behavior in online informal learning tasks that require knowledge acquisition.

\section{CONCLUSIONS AND IMPLICATIONS}

Designing effective online informal learning environments have become increasingly important for organizations to enhance their employees' knowledge management performance. This study investigated the factors affecting knowledge acquisition in the online informal learning process of adult workers. The research model provides a more comprehensive insight into online information seeking and sharing behavior, while exploring adult workers' perceived abilities towards knowledge construction in the context of their workplace. The 
findings suggest that information querying plays an important role in influencing information differentiation, while information differentiation also shows effective explanatory power in adult workers' online communication self-efficacy and information evaluation and extraction performance. Furthermore, the construct of information evaluation and extraction performance shows positive effects on workers' knowledge acquisition. The findings confirm that critical elements of the ISP model could contribute significantly in predicting adult workers' engagement in online informal learning activities.

The results of the study give rise to two important implications for the development of human resource management in organizations. First, information literacy training related to information seeking needs to be arranged in organizations' training initiatives. The concepts of the ISP model can be incorporated into the training courses designed to empower employees' digital information literacy. The second recommendation, as suggested by Lohman (2009), is to develop friendly online information sharing and collaboration tools, which can facilitate adult workers to gather and analyze information. Hence, the proposed model in this paper can be particularly useful when applied in designing an online learning portal in organizations. In addition to providing training in digital information literacy for employees, the knowledge base and Web 2.0 applications can be included in the learning portal to help improve knowledge creation, sharing, and retention within the organization. From an adoption point, training administrators should design implementation plans that stress fun and usefulness of Web 2.0 applications in facilitating employees to communicate better and learn.

\section{LIMITATIONS AND FUTURE RESEARCH}

This study collected research data from civil servants in Taiwan that might not be representative of adult workers in other countries. Also, focusing on the relationship between selected variables of the research model is limiting, as other factors could also impact adult workers' knowledge acquisition in the online informal learning activities. Thus, the results must be interpreted and generalized with caution. Future research can adopt the research model to exam a more comprehensive population or extend the research model to investigate other phenomena related to online informal learning. Additional research is strongly needed to advance the understanding of adult workers' engagement in online information learning environments. In addition to the investigation of the cognition, affection, and action aspects of users' information search behavior, environmental and contextual factors such as computer access, ICT structure and support, relationships with colleagues, and monetary awards, can be considered to comprehend adult workers' decision-making processes in online informal learning situations. Qualitative approaches may also provide a better understanding of adult workers' experiences toward using digital tools facilitating informal learning in the workplace.

\section{ACKNOWLEDGEMENTS}

This work was supported by the Ministry of Science and Technology, Taiwan, under grant number [102-2410H-260-036-].

\section{REFERENCES}

Ajjan, H., Hartshorne, R., \& Buechler, S. (2012). Investigating Web 2.0 application impacts on knowledge workers' decisions and performance. Information Resources Management Journal, 25(4), 65-83.

Berg, S. A., \& Chyung, S. Y. (2008). Factors that influence informal learning in the workplace. Journal of Workplace Learning, 20(4), 229-244. doi:10.1108/13665620810871097

Chin, W. W. (1998). The partial least squares approach to structural equation modeling. Modern methods for business research, 295(2), 295-336.

Clough, G., Jones, A. C., McAndrew, P., \& Scanlon, E. (2008). Informal learning with PDAs and smartphones. Journal of Computer Assisted Learning, 24(5), 359-371. doi:10.1111/j.1365-2729.2007.00268.x

Cohen, J. (1988). Statistical power analysis for the behavioral sciences. Hilsdale, NJ: Lawrence Earlbaum Associates.

Eraut, M. (2004). Informal learning in the workplace. Studies in Continuing Education, 26(2), 247-273. doi:10.1080/158037042000225245

Feng, L., \& Ha, J.-L. (2016). Effects of teachers' information literacy on lifelong learning and school effectiveness. Eurasia Journal of Mathematics, Science \& Technology Education, 12(6), 1653-1663.

Fornell, C., \& Larcker, D. F. (1981). Evaluating structural equation models with unobservable variables and measurement error. Journal of marketing research, 18(1), 39-50.

Gu, J., Churchill, D., \& Lu, J. (2014). Mobile Web 2.0 in the workplace: A case study of employees' informal learning. British Journal of Educational Technology, 45(6), 1049-1059. doi:10.1111/bjet.12179 
Hair Jr, J. F., Hult, G. T. M., Ringle, C., \& Sarstedt, M. (2016). A primer on partial least squares structural equation modeling (PLS-SEM). Sage Publications.

Hair, J. F., Black, W. C., Babin, B. J., Anderson, R. E., \& Tatham, R. L. (2006). Multivariate data analysis (6th ed.). Upper Saddle River, NJ: Pearson Prentice Hall.

Hair, J. F., Ringle, C. M., \& Sarstedt, M. (2011). PLS-SEM: Indeed a silver bullet. Journal of Marketing Theory and Practice, 19(2), 139-152.

Henseler, J., Ringle, C. M., \& Sarstedt, M. (2015). A new criterion for assessing discriminant validity in variancebased structural equation modeling. Journal of the Academy of Marketing Science, 43(1), 115-135.

Ho, L.-A., Kuo, T.-H., \& Lin, B. (2012). The mediating effect of website quality on internet searching behavior. Computers in Human Behavior, 28(3), 840-848. doi:10.1016/j.chb.2011.11.024

Hung, M.-L., Chou, C., Chen, C.-H., \& Own, Z.-Y. (2010). Learner readiness for online learning: Scale development and student perceptions. Computers \& Education, 55(3), 1080-1090. doi:10.1016/j.compedu.2010.05.004

Kao, C. -P., \& Chien, H. -M. (2017). Web-searching to learn: The role of Internet self-efficacy in pre-school educators' conceptions and approaches. EURASIA Journal of Mathematics Science and Technology Education, 13(6), 20392056.

Kassens-Noor, E. (2012). Twitter as a teaching practice to enhance active and informal learning in higher education: The case of sustainable tweets. Active Learning in Higher Education, 13(1), 9-21.

Kuhlthau, C. C. (1991). Inside the search process: Information seeking from the user's perspective. Journal of the American Society for Information Science, 42(5), 361-371.

Kuhlthau, C.C., Heinström, J. \& Todd, R.J. (2008). The 'information search process' revisited: is the model still useful? Information Research, 13(4). Retrieved from http://www.informationr.net/ir/13-4/paper355.html

Lai, H.-J., \& Wang, C.-Y. (2012). Examining public librarians' Information literacy, self-directed learning readiness, and e-learning attitudes: A study from Taiwan. Malaysian Journal of Library \& Information Science, 17(2), 101125.

Li, C., Shi, X., \& Dang, J. (2014). Online communication and subjective well-being in chinese college students: The mediating role of shyness and social self-efficacy. Computers in Human Behavior, 34, 89-95.

Liu, S.-H. (2017). Relationship between the factors influencing online help-seeking and self-regulated learning among Taiwanese preservice teachers. Computers in Human Behavior, 72, 38-45.

Lohman, M. C. (2006). Factors influencing teachers' engagement in informal learning activities. Journal of Workplace Learning, 18(3), 141-156.

Lohman, M. C. (2009). A survey of factors influencing the engagement of information technology professionals in informal learning activities. Information Technology, Learning, and Performance Journal, 25(1), 43-53.

Macdonald, I., \& Chiu, J. (2011). Evaluating the viability of mobile learning to enhance management training. Canadian Journal of Learning and Technology, 37(1).1-13.

Marsick, V.J., Watkins, K.E., Callahan, M.W., \& Volpe, M. (2009). Informal and incidental learning in the workplace. In M. C. Smith \& N. DeFrates-Densch (Eds.), Handbook of research on adult learning and development (pp. 570-599). New York, NY: Routledge.

Merriam, S., Caffarella, R., \& Baumgartner, L. (2007). Learning in adulthood: A comprehensive guide. San Francisco, CA: John Wiley.

Milligan, C., Littlejohn, A., \& Margaryan, A. (2014). Workplace Learning in Informal Networks. Journal of Interactive Media in Education, 2014(1), p.Art. 6. doi:10.5334/2014-06

Mills, L. A., Knezek, G., \& Khaddage, F. (2014). Information seeking, information sharing, and going mobile: Three bridges to informal learning. Computers in Human Behavior, 32(0), 324-334. doi:10.1016/j.chb.2013.08.008

Nikolova, I., Van Ruysseveldt, J., De Witte, H., \& Syroit, J. (2014). Work-based learning: Development and validation of a scale measuring the learning potential of the workplace (LPW). Journal of Vocational Behavior, $84(1), 1-10$

Noe, R. A., Tews, M. J., \& Marand, A. D. (2013). Individual differences and informal learning in the workplace. Journal of Vocational Behavior, 83(3), 327-335. doi:10.1016/j.jvb.2013.06.009

Nunnally, J. (1978). Psychometric methods. New York: McGraw-Hill.

Oh, H. J., Ozkaya, E., \& LaRose, R. (2014). How does online social networking enhance life satisfaction? The relationships among online supportive interaction, affect, perceived social support, sense of community, and life satisfaction. Computers in Human Behavior, 30, 69-78. 
Puijenbroek, T., Poell, R. F., Kroon, B., \& Timmerman, V. (2014). The effect of social media use on work-related learning. Journal of Computer Assisted Learning, 30(2), 159-172. doi:10.1111/jcal.12037

Sackey, D. J., Nguyen, M.-T., \& Grabill, J. T. (2015). Constructing learning spaces: What we can learn from studies of informal learning online. Computers \& Composition, 35, 112-124. doi:10.1016/j.compcom.2015.01.004

Savolainen, R. (2015). Approaching the affective factors of information seeking: The viewpoint of the information search process model. Information Research: An International Electronic Journal, 20(1), 1-39.

Schugurensky, D. (2000). The forms of informal learning: Towards a conceptualization of the field. Retrieved from https://tspace.library. utoronto.ca/bitstream/1807/2733/2/19formsofinformal.pdf

Spagnoletti, P., Za, S., \& North-Samardzic, A. (2013). Fostering informal learning at the workplace through digital platforms and information infrastructures. Retrieved from http://mo.bf.rmit.edu.au/acis2013/141.pdf

Stoffregen, J., Pawlowski, J. M., \& Pirkkalainen, H. (2015). A barrier framework for open e-learning in public administrations. Computers in Human Behavior, 51, Part B, 674-684. doi:10.1016/j.chb.2014.12.024

Tabatabai, D., \& Shore, B. M. (2005). How experts and novices search the web. Library \& Information Science Research (07408188), 27(2), 222-248. doi:10.1016/j.lisr.2005.01.005

Walraven, A., Brand-Gruwel, S., \& Boshuizen, H. P. A. (2009). How students evaluate information and sources when searching the world wide web for information. Computers $\mathcal{E}$ Education, 52(1), 234-246. doi:10.1016/j.compedu.2008.08.003

Wihak, C., \& Hall, G. (2011). Work-related informal learning: Research and practice in the Canadian context. Toronto, Ontario: Centre for Workplace Skills.

Zhang, B., Yin, C., David, B., Xiong, Z., \& Niu, W. (2016). Facilitating professionals' work-based learning with context-aware mobile system. Science of Computer Programming, 129, 3-19. doi:10.1016/j.scico.2016.01.008

\section{http://www.ejmste.com}

